\title{
Dihydromyricetin protects against lipopolysaccharide-induced cardiomyocyte injury through the toll-like receptor-4/nuclear factor- $\kappa B$ pathway
}

\author{
MENG-QIAO ZHOU, LING SHAO, JING WU, NA PENG, LU-PING JIN, \\ GUO-ZHEN WEI, WEI CHENG and CHANG-JIN DENG \\ Department of Cardiology, The First People's Hospital of Jingmen, Jingmen, Hubei 448000, P.R. China
}

Received May 1, 2016; Accepted March 24, 2017

DOI: $10.3892 / \mathrm{mmr} .2017 .7742$

\begin{abstract}
Dihydromyricetin (DHM) is a bioactive flavonoid compound extracted from the stems and leaves of Ampelopsis grossedentata. Previous studies have indicated that DHM has antioxidation and antitumor capabilities, while the effect of DHM on lipopolysaccharide (LPS)-induced cardiomyocyte injury has not been clarified. Therefore, the aim of the present study was to investigate the effect of DHM on LPS-induced cardiomyocyte injury. In the present study, cardiomyocytes were randomized to the control (PBS), LPS and DHM + LPS groups. The LPS group was treated with $10 \mu \mathrm{g} / \mathrm{ml}$ LPS for $12 \mathrm{~h}$ and the DHM + LPS group was treated with 100 or $25 \mu \mathrm{M}$ DHM $12 \mathrm{~h}$ prior to treatment with LPS. The protective effect of DHM on LPS-induced cardiomyocytes injury was evaluated by Cell Counting kit- 8 assay, TUNEL staining, reverse transcription-quantitative polymerase chain reaction and western blot analysis. The results demonstrated that LPS treatment led to cardiomyocyte apoptosis, and these effects were significantly attenuated by DHM. Furthermore, LPS treatment downregulated the expression of B-cell lymphoma 2 apoptosis regulator (Bcl-2) and induced increased expression of Bcl-2-associated $\mathrm{X}$ apoptosis regulator (Bax). Additionally, DHM treatment reversed LPS-induced changes in Bcl-2 expression and Bax expression in cardiomyocytes, and rescued cells from apoptosis. In addition, increased mRNA expression levels of tumor necrosis factor- $\alpha$ and interleukin-6 induced by LPS were attenuated following treatment with DHM. Further investigation demonstrated that DHM suppressed the activation of toll-like receptor-4 (TLR4), which is involved in regulating the downstream signaling pathway of nuclear factor- $\mathrm{\kappa B}(\mathrm{NF}-\kappa \mathrm{B})$. DHM attenuated LPS-induced
\end{abstract}

Correspondence to: Dr Chang-Jin Deng, Department of Cardiology, The First People's Hospital of Jingmen, 67 Xiangshan Avenue, Jingmen, Hubei 448000, P.R. China

E-mail: dengchangjin18@outlook.com

Key words: dihydromyricetin, lipopolysaccharide, cardiomyocytes, apoptosis, inflammation, toll-like receptor-4 cardiomyocyte injury, the potential mechanism responsible for this effect may involve inhibition of TLR4 activation and subsequent regulation of the associated downstream signaling pathway of NF-kB. The current study indicates that DHM may protect cardiomyocytes against LPS-induced injury by inhibition of the TLR4/NF-KB signaling pathway. The results of the present study may provide support for the development DHM as a strategy for the treatment of heart failure in septic shock.

\section{Introduction}

Lipopolysaccharide (LPS), the bacterial endotoxin, is considered to be the primary factor responsible for multi-organ failure in septic shock (1). The myocardium is one of the organs affected by septic shock, which is a major cause of mortality (2). It has been previously demonstrated that LPS activates caspases in cardiomyocytes, which induces end-stage nuclear apoptosis, cleavage of cardiac myofilament proteins and sarcomere disorganization (3). LPS-induced myocardial dysfunction is mediated by various proinflammatory mediators, including tumor necrosis factor (TNF)- $\alpha$ and interleukin 1 (IL-1), which may be responsible for LPS-induced multiple organ failure, including heart failure $(4,5)$. Toll-like receptor-4 (TLR4), which is a type of pattern recognition receptor, is considered to be involved in the LPS-induced innate immune response (6). The TLR4 predominantly expressed in cardiomyocytes recognizes LPS and triggers the recruitment of adaptors, including myeloid differentiation factor 88 and Toll/IL-1 receptor domain-containing adaptor protein-inducing interferon- $\beta(7)$. These two pathways result in the activation of nuclear factor- $\kappa \mathrm{B}(\mathrm{NF}-\kappa \mathrm{B})$, a key transcription factor involved in inflammatory activation (7). Therefore, pharmacological interventions that disrupt the TLR4-induced inflammatory response in cardiomyocytes may be a promising approach for the treatment of certain cardiovascular diseases.

Ampelopsis, a plant of the Vitaceae family and widely used in Chinese traditional medicine for treating liver disorders (8), is widely distributed in tropical and subtropical regions (9). Dihydromyricetin (DHM) is a type of flavonoid compound, which is extracted from the stems and leaves of Ampelopsis grossedentata (10). Previous studies have reported that DHM functions as an anti-insulin resistance (11), 
antitumor (12), anti-inflammatory (13) and antioxidative (14) agent. DHM is reported to suppress the levels of proinflammatory cytokines and increase the level of anti-inflammatory cytokines in macrophage cells (13). Recently, it has been reported that DHM protects against angiotensin II-induced cardiomyocyte hypertrophy by augmenting nitric oxide production (15). In addition, existing data also indicates that DHM protects against Adriamycin-induced heart injury by protecting myocardial cells from apoptosis (16). Therefore, the current study aimed to investigate whether DHM protects against LPS-induced cardiomyocyte injury and to identify the mechanisms involved.

\section{Materials and methods}

H9c2 cardiomyocyte culture. The H9c2 embryonic rat heart-derived cell line was obtained from The Cell Bank of Type Culture Collection of Chinese Academy of Sciences (Shanghai, China). DHM was purchased from Sigma-Aldrich (Merck KGaA, Darmstadt, Germany) and was dissolved at a concentration of $50 \mathrm{mM}$ in dimethysulfoxide (Sigma-Aldrich; Merck $\mathrm{KGaA}$ ) for storage at $-20^{\circ} \mathrm{C}$. Cells were cultured in Dulbecco's modified Eagle's medium (Gibco; Thermo Fisher Scientific, Inc., Waltham, MA, USA) supplemented with 10\% fetal bovine serum (Gibco; Thermo Fisher Scientific, Inc.), penicillin $(100 \mathrm{U} / \mathrm{ml})$ and streptomycin $(100 \mathrm{mg} / \mathrm{ml}$; Gibco; Thermo Fisher Scientific, Inc.) in a humidified incubator with an atmosphere of $5 \% \mathrm{CO}_{2}$ at $37^{\circ} \mathrm{C}$. Cells were seeded at a density of $1 \times 10^{6}$ per well onto 6 -well culture plates for mRNA extraction, $5 \times 10^{3}$ cells per well in 96-well plates for terminal deoxynucleotidyl transferase dUTP nick-end labeling (TUNEL) analysis and $1 \times 10^{7}$ per well onto culture dishes $(100 \mathrm{~mm})$ for protein extraction. Cells were cultured in serum-free medium for $8 \mathrm{~h}$ at $37^{\circ} \mathrm{C}$ and pretreated with DHM $(25,50$ and $100 \mu \mathrm{M})$ or PBS for $12 \mathrm{~h}$ prior to LPS $(10 \mu \mathrm{g} / \mathrm{ml}$; L2630; Sigma-Aldrich; Merck KGaA) stimulation for $12 \mathrm{~h}$ at $37^{\circ} \mathrm{C}$.

Cell viability assay. Cell viability was evaluated by Cell Counting kit-8 (CCK-8; Sigma-Aldrich; Merck KGaA) assay according to the manufacturer's instructions. Briefly, $10 \mu \mathrm{l}$ CCK-8 solution was added to each well of a 96-well plate $\left(1 \times 10^{3}\right.$ cells per well) and, following $4 \mathrm{~h}$ incubation at $37^{\circ} \mathrm{C}$, the absorbance was measured at $450 \mathrm{~nm}$ using the BioTek Synergy HT reader (BioTek Instruments, Inc., Winooski, VT, USA). The effect of DHM on cell viability was expressed as the percentage cell viability compared with the control group, which was set at $100 \%$.

TUNEL staining. TUNEL assays were performed using the ApopTag ${ }^{\circledR}$ Plus Fluorescein In Situ Apoptosis Detection kit (EMD Millipore, Billerica, MA, USA) to label apoptotic nuclei, according to the manufacturer's instructions. Briefly, following $12 \mathrm{~h}$ pretreatment with DHM, cells were incubated with LPS for $12 \mathrm{~h}$ and subsequently fixed on coverslips in $1 \%$ paraformaldehyde in PBS (Sinopharm Chemical Reagent Co., Ltd., Shanghai, China) at room temperature for $5 \mathrm{~min}$. After washing with PBS three times, cells were stained with TUNEL reagents (EMD Millipore) and 4', 6-diamidino-2-phenylindole (DAPI; $0.3 \mathrm{mmol} / \mathrm{l}$; Invitrogen; Thermo Fisher

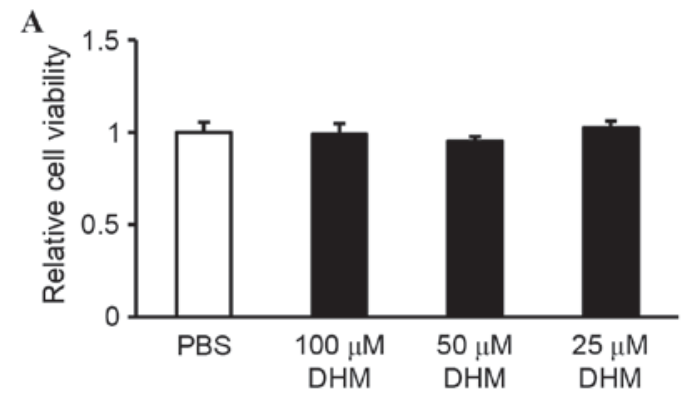

B

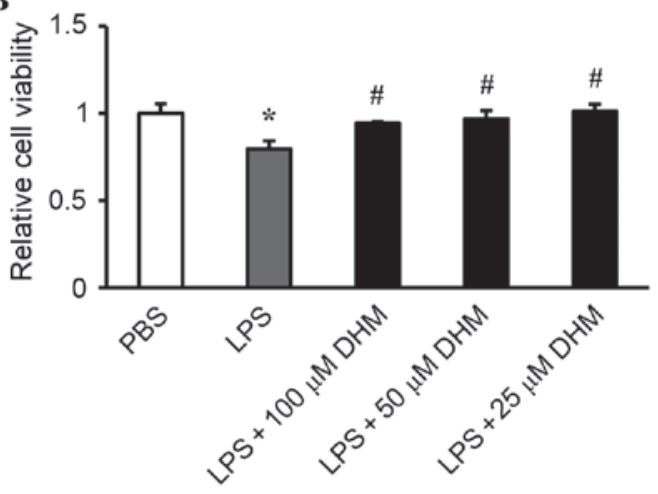

Figure 1. Effect of DHM on cell viability measured by Cell Counting kit- 8 assay. (A) Treatment with 100,50 or $25 \mu \mathrm{M}$ DHM for $12 \mathrm{~h}$ did significantly affect cell viability compared with the PBS control group. (B) Treatment with 100,50 or $25 \mu \mathrm{M}$ DHM for $12 \mathrm{~h}$ and $10 \mu \mathrm{g} / \mathrm{ml}$ LPS for $12 \mathrm{~h}$ increased cell viability compared with the LPS-only group. ${ }^{*} \mathrm{P}<0.05$ vs. PBS group and ${ }^{\#} \mathrm{P}<0.05$ vs. LPS group. DHM, dihydromyricetin; LPS, lipopolysaccharide.

Scientific, Inc.) for $1 \mathrm{~min}$, and observed under a fluorescence microscope (BX51; Olympus Corporation, Tokyo, Japan). The index of cell apoptosis was calculated as the percentage of apoptotic nuclei/total number of nuclei ( $\mathrm{n}=10$ fields of view).

Western blot analysis. Cells in dishes $\left(1 \times 10^{7}\right.$ per well) were harvested and lysed in radioimmunoprecipitation assay (RIPA) lysis buffer with shaking for 15 min on ice. RIPA assay lysis buffer contained the following per ml: RIPA (720 $\mu \mathrm{l}$; Beyotime Institute of Biotechnology, Haimen, China), PMSF $(20 \mu \mathrm{l} ; 1 \mathrm{mM})$, cOmplete ${ }^{\mathrm{TM}}$ Protease Inhibitor Cocktail (100 $\mu$; Roche; Sigma-Aldrich; Merck KGaA), PhosStop ${ }^{\mathrm{TM}}$ (100 $\mu \mathrm{l}$; Roche; Sigma-Aldrich; Merck KGaA), NaF (50 $\mu \mathrm{l}$; $1 \mathrm{mM})$ and $\mathrm{Na}_{3} \mathrm{VO}_{4}(10 \mu \mathrm{l})$. The protein concentration was measured using a bicinchoninic acid protein assay kit with a BioTek Synergy HT reader (BioTek Instruments, Inc.). The extracted protein $(50 \mu \mathrm{g})$ from each sample was separated by $8-12 \%$ SDS-PAGE and the proteins were transferred onto polyvinylidene difluoride membranes. The membranes were blocked with 5\% non-fat milk powder for $1 \mathrm{~h}$ at room temperature and were then incubated with primary antibodies overnight at $4^{\circ} \mathrm{C}$. The primary antibodies used were as follows: B-cell lymphoma 2 apoptosis regulator (Bcl-2; cat. no. 2870; 1:1,000; Cell Signaling Technology, Inc.), Bcl-2-associated X apoptosis regulator (Bax; cat. no. 2772; 1:1,000; Cell Signaling Technology, Inc., Danvers, MA, USA), total (T)-NF-кB p65 (cat. no. 8242; 1:1,000; Cell Signaling Technology, Inc.), phosphorylated (p)-NF- $\kappa \mathrm{B}$ p65 (cat. no. 3033; 1:1,000; Cell Signaling Technology, Inc.), TLR4 (cat. no. sc-30002; 1:200; Santa Cruz Biotechnology, Inc., Dallas, Texas, USA) and 
A

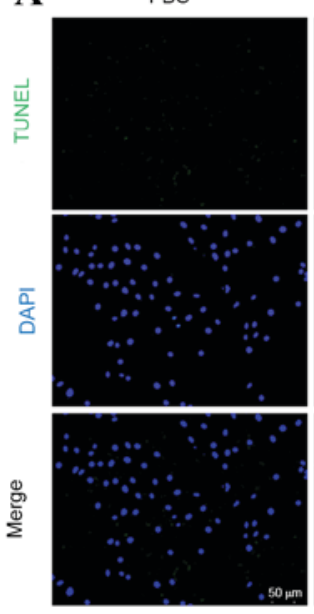

C

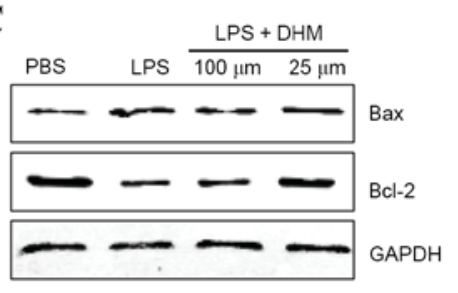

LPS

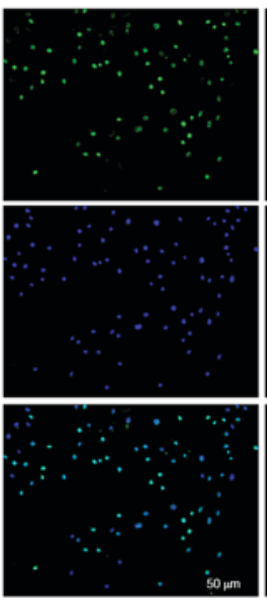

LPS $+100 \mu \mathrm{m}$ DHM

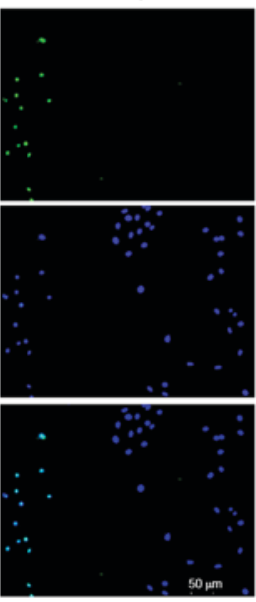

D

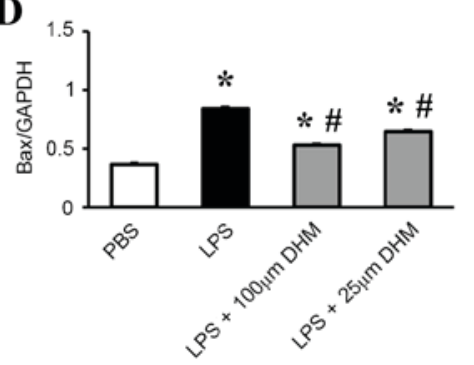

LPS $+25 \mu \mathrm{m}$ DHM

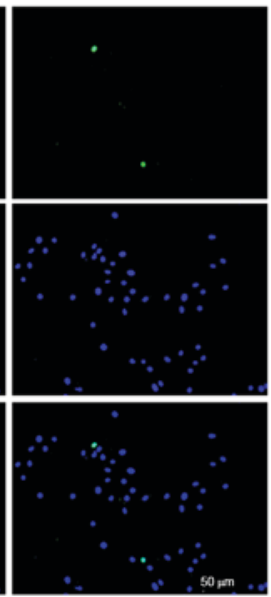

B

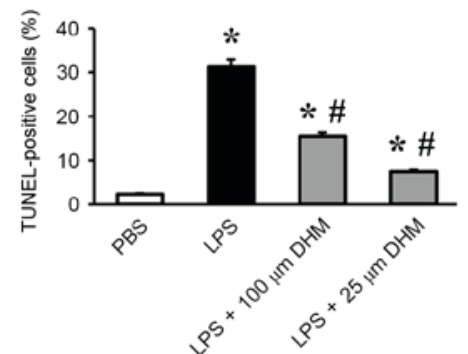

Figure 2. Effect of DHM on cell apoptosis. (A) Representative TUNEL and DAPI-stained images investigating the effect of 100 and $25 \mu \mathrm{M}$ DHM on cell apoptosis following stimulation with LPS $(10 \mu \mathrm{g} / \mathrm{ml})$ for $12 \mathrm{~h}$. Original magnification, x200. (B) Quantitative results of TUNEL analysis. (C) Representative western blot images investigating the effect of 100 and $25 \mu \mathrm{M}$ DHM on protein levels of Bax and Bcl-2 in response to LPS. (D) Quantitative results of western blot analysis. ${ }^{*} \mathrm{P}<0.05$ vs. PBS group and ${ }^{\#} \mathrm{P}<0.05$ vs. LPS group. DHM, dihydromyricetin; TUNEL, terminal deoxynucleotidyl transferase dUTP nick-end labeling; LPS, lipopolysaccharide; Bax, Bcl-2-associated X apoptosis regulator; Bcl-2, B-cell lymphoma 2 apoptosis regulator.
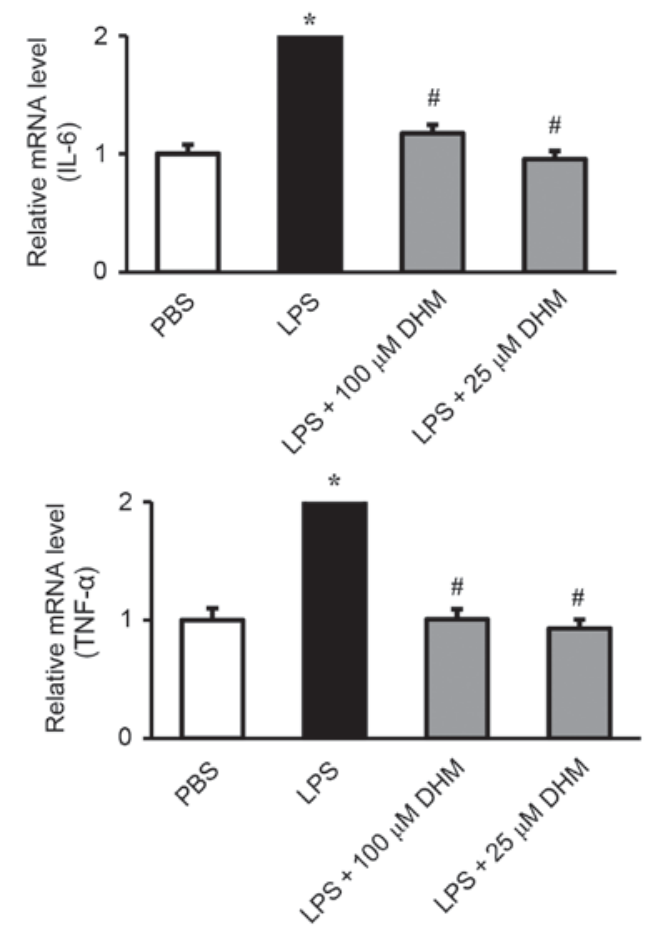

Figure 3. Effect of DHM on the mRNA expression of inflammatory mediators. Reverse transcription-quantitative polymerase chain reaction analysis of the mRNA levels of IL- 6 and TNF- $\alpha$ induced by pretreatment with 100 and $25 \mu \mathrm{M}$ DHM for $12 \mathrm{~h}$ followed by $10 \mu \mathrm{g} / \mathrm{ml}$ LPS for $12 \mathrm{~h} .{ }^{*} \mathrm{P}<0.05 \mathrm{vs}$. PBS group and " $\mathrm{P}<0.05$ vs. LPS group. DHM, dihydromyricetin; IL, interleukin; $\mathrm{TNF}-\alpha$, tumor necrosis factor- $\alpha$; LPS, lipopolysaccharide.
GAPDH (cat. no. sc-25778; 1:200; Santa Cruz Biotechnology, Inc.). The membranes were subsequently incubated with IRDye 800CW-conjugated secondary antibodies (LI-COR Biosciences; cat. no. 926-32211; 1:200; Lincoln, NE, USA) for $1 \mathrm{~h}$ at room temperature. The blots were scanned using an Odyssey ${ }^{\circledR} \mathrm{Fc}$ infrared scanner, allowing for simultaneous detection of two targets (phosphorylated and total protein) within the same experiment (LI-COR Biosciences). The specific protein expression levels were normalized against the expression of GAPDH by Quantity One software (version 4.6.2; Bio-Rad Laboratories, Inc., Hercules, CA, USA).

Reverse transcription-quantitative polymerase chain reaction $(R T-q P C R)$. Cells in 6 -well plates $\left(1 \times 10^{6}\right.$ per well) were harvested and total RNA was extracted using TRIzol (Thermo Fisher Scientific, Inc.). The yield and purity levels of the RNA were spectrophotometrically estimated using A260/A280 and A230/A260 ratios, obtained via a SmartSpec Plus Spectrophotometer (Bio-Rad Laboratories, Inc.). The RNA (2 mg each sample) was reverse transcribed into cDNA using a Transcriptor First Strand cDNA Synthesis kit (Roche Diagnostics, Basel, Switzerland), according to the manufacturer's protocol. The PCR amplifications were quantified using the LightCycler ${ }^{\circledR} 480$ SYBR $^{\circledR}$ Green I Master Mix (Roche Diagnostics), according to the manufacturer's protocol, in the LightCycler ${ }^{\circledR} 480$ Real-Time PCR System (Roche Diagnostics). Briefly, following a $5 \mathrm{~min}$ initial 
A

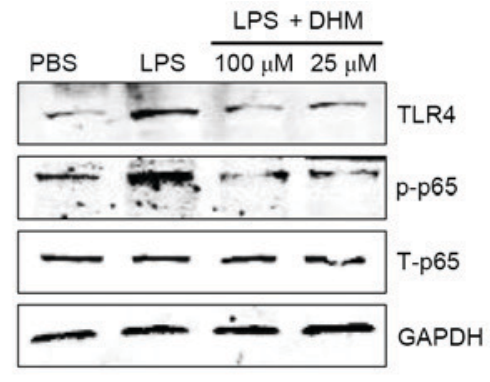

C
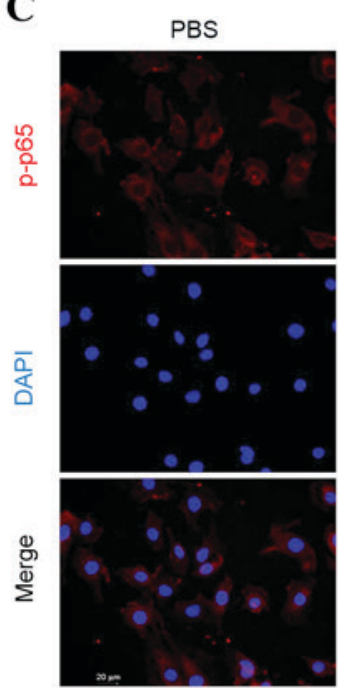

B

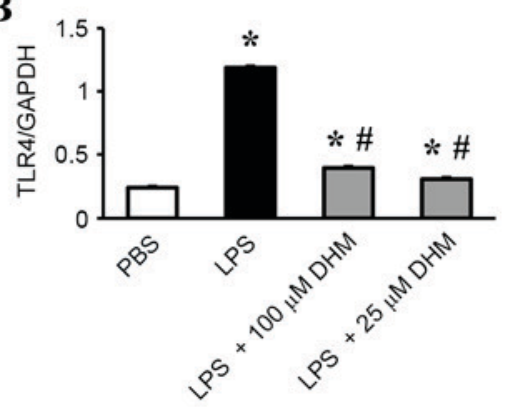

LPS

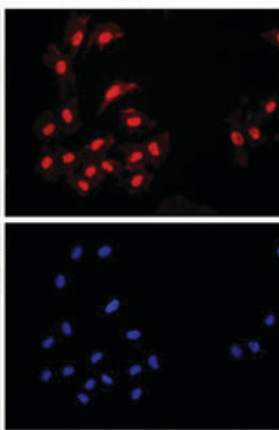

LPS $+100 \mu \mathrm{M} \mathrm{DHM}$
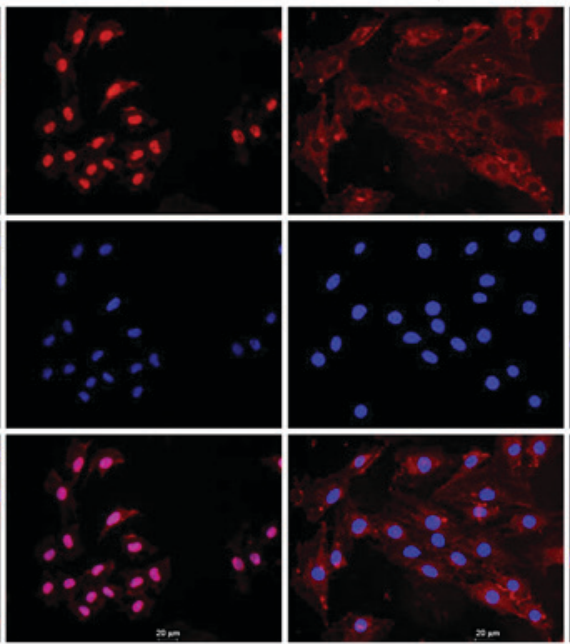

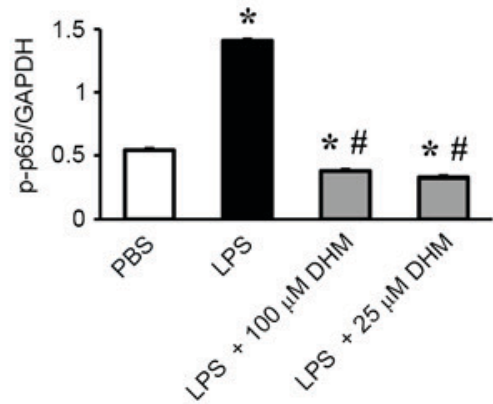

LPS $+25 \mu \mathrm{M}$ DHM

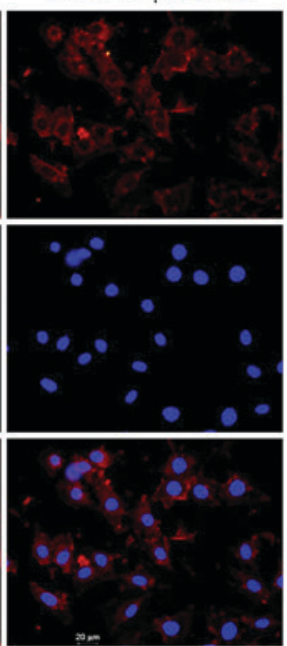

Figure 4. Effect of DHM on the activation of the TLR4/NF- $\mathrm{B}$ pathway. (A) Representative blots and (B) quantitative results of western blot analysis to determine the effect of DHM on the activation of TLR4/NF- $\kappa$ B pathways, including TLR4, p-NF- $\mathrm{B}$ p65 and T-NF- $\kappa$ B p65. (C) Effect of DHM on the LPS-induced nuclear translocation of $\mathrm{NF}-\kappa \mathrm{B}$ p65. Magnification, $\mathrm{x} 200$. * $\mathrm{P}<0.05$ vs. PBS group and ${ }^{\#} \mathrm{P}<0.05$ vs. LPS group. DHM, dihydromyricetin; TLR4,

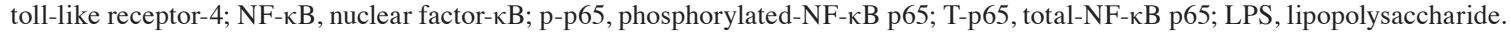

denaturation at $95^{\circ} \mathrm{C}$, a total of 42 primer-extension cycles were carried out. Each cycle consisted of a $10 \mathrm{sec}$ denaturation step at $95^{\circ} \mathrm{C}$, a $20 \mathrm{sec}$ annealing step at $60^{\circ} \mathrm{C}$ and a $20 \mathrm{sec}$ incubation at $72^{\circ} \mathrm{C}$ for extension. A final extension step was performed at $72^{\circ} \mathrm{C}$ for $10 \mathrm{~min}$. The double standard curve was used to quantify the PCR results. Calibrator normalized ratio $=($ concentration of sample target/concentration of sample reference)/(concentration of calibrator target/concentration of calibrator reference). The results were normalized to the mRNA expression of GAPDH by using the $\Delta \Delta \mathrm{Cq}$ method (17). The experiment was repeated three times. The sequences of the oligonucleotide primers (Sangon Biotech Co., Ltd., Shanghai, China) were as follows: TNF- $\alpha$ forward, 5'-AGCATGATC CGAGATGTGGAA-3' and reverse, 5'-TAGACAGAAGAG CGTGGTGGC-3'; IL-6 forward, 5'-GTTGCCTTCTTGGGA CTGATG-3', and reverse, 5'-ATACTGGTCTGTTGTGGG TGGT-3'; and GAPDH forward, 5'-GACATGCCGCCTGGA GAAAC-3' and reverse 5'-AGCCCAGGATGCCCTTTAGT-3'.

Immunofluorescence staining. Briefly, the cells $\left(5 \times 10^{3}\right.$ per well) were washed with PBS, fixed with $1 \%$ paraformaldehyde for $5 \mathrm{~min}$ at room temperature, permeabilized in $0.1 \%$ Triton X-100 (Amresco, LLC, Solon, OH, USA) in PBS for $5 \mathrm{~min}$ at room temperature and blocked with $8 \%$ goat serum (Beyotime Institute of Biotechnology) for $1 \mathrm{~h}$ at room temperature. Cells were then stained with anti-p-NF- $\kappa$ B p65 (cat. no. BS4135; Bioworld Technology, Inc., St. Louis Park,
MN, USA) overnight at a dilution of 1:100 in 1\% goat serum at $4^{\circ} \mathrm{C}$. Following 5 washes in PBS, cells were incubated with Alexa Fluor 568 goat anti-rabbit IgG secondary antibody (cat. no. A-11011; 1:200; Invitrogen; Thermo Fisher Scientific, Inc.) for $60 \mathrm{~min}$ at room temperature. Following 6 washes in PBS, cells on coverslips were mounted onto glass slides using SlowFade ${ }^{\circledR}$ Gold Antifade Mountant with DAPI (Invitrogen; Thermo Fisher Scientific, Inc.).

Statistical analysis. Data are presented as the mean \pm standard error of the mean. Differences among the groups were determined by one way analysis of variance followed by a post-hoc Tukey test. Comparisons between two groups were performed using the unpaired Student's t-test. Statistical analyses were performed using SPSS version 13.0 (SPSS, Inc., Chicago, IL, USA). $\mathrm{P}<0.05$ was considered to indicate a statistically significant difference.

\section{Results}

Effect of DHM on cell viability. The potential cytotoxicity of DHM was examined by CCK-8 assay. H9c2 cells were incubated with varying concentrations of DHM (100, 50 and $25 \mu \mathrm{M}$ ) for $12 \mathrm{~h}$. Cell viability in DHM-treated cells was not significantly different compared with that of control cells treated with PBS, indicating that DHM $(100,50$ and $25 \mu \mathrm{M})$ did not cause cytotoxicity in H9c2 cells (Fig. 1A). Stimulation 
with LPS for $12 \mathrm{~h}$ significantly reduced the cell viability, while 100, 50 and $25 \mu \mathrm{M}$ concentrations of DHM pretreatment attenuated LPS-induced cytotoxicity (Fig. 1B).

DHM attenuates LPS-induced apoptosis in H9c2 cells. TUNEL staining was used to identify the potential protective role of DHM on LPS-induced apoptosis in H9c2 cells. A significant increase in the number of TUNEL-positive nuclei was observed in cells incubated with LPS compared with control cells, and DHM (100 and $25 \mu \mathrm{M})$ pretreatment significantly reduced LPS-induced cell apoptosis (Fig. 2A and B). In addition, DHM pretreatment decreased the levels of expression of Bax protein, while increasing the $\mathrm{Bcl}-2$ protein expression levels in H9c2 cells following LPS stimulation (Fig. 2C and D).

DHM inhibits the expression of inflammatory genes induced by LPS in H9c2 cells. The effect of DHM on the induction of IL- 6 and TNF- $\alpha$ in response to LPS was measured by RT-qPCR. LPS significantly stimulated the release of IL-6 and TNF- $\alpha$. Pretreatment with DHM (100 and $25 \mu \mathrm{M})$ significantly attenuated the LPS-induced increase in IL-6 and TNF- $\alpha$ (Fig. 3).

DHM reduces the activation of TLR4/NF- $\kappa B$ signaling in response to LPS. The mechanisms underlying the anti-inflammatory effects of DHM on LPS-treated H9c2 cells was investigated by western blot analysis. The results demonstrated that LPS significantly increased the expression level of TLR4 and subsequently increased the levels of p-NF- $\kappa \mathrm{B}$ p65 (Fig. 4A and $\mathrm{B}$ ). While 100 and $25 \mu \mathrm{M}$ DHM decreased expression of TLR4 and subsequently decreased the levels of p-NF- $\kappa \mathrm{B}$ p65 (Fig. 4A and B). In addition, treatment with 100 and $25 \mu \mathrm{M}$ DHM reduced LPS-induced increases in the nuclear translocation of NF- $\kappa$ B p65 as determined by immunofluorescence staining (Fig. 4C).

\section{Discussion}

DHM has been previously demonstrated to be an anti-inflammatory (13) and antioxidative (14) compound. The present study demonstrated a novel role of DHM in the protection of cardiomyocytes from LPS-induced injury. DHM attenuated LPS-induced apoptosis in cardiomyocytes by reducing Bax expression and the upregulation of Bcl-2 expression. DHM also attenuated LPS-induced inflammatory response by the inhibition of the TLR4/NF- $\kappa \mathrm{B}$ signaling cascade.

Sepsis is a major consequence of infectious diseases, which causes injury to multiple organs, including injury to the cardiovascular system (18). It has been demonstrated that cardiomyocytes are the major local source of proinflammatory cytokines in the myocardium during sepsis (19). These proinflammatory cytokines, including TNF- $\alpha$, IL- 6 and IL- $1 \beta$ are responsible for LPS-induced cardiac dysfunction and myocardial depression, which may cause cardiomyocyte apoptosis and heart failure $(20,21)$. Therefore, blocking inflammatory signaling may produce beneficial effects in the dysfunctional heart. Ampelopsis grossedentata has been used for treating pharyngitis in traditional Chinese medicine for hundreds of years. Hou et al (13) reported that DHM, a major bioactive component of Ampelopsis grossedentata, suppresses the release of TNF- $\alpha$, IL- 6 and IL-1 $\beta$ in macrophage cells (13).
The present study demonstrated that DHM downregulated the expression of TNF- $\alpha$ and IL-6 in LPS-stimulated H9c2 cells, indicating an anti-inflammatory effect of DHM in cardiomyocytes.

Inflammatory mediators cause cardiac cytotoxicity and lead to cardiomyocyte apoptosis, thereby promoting cardiac dysfunction (22). A well-balanced interplay between antiand proapoptotic Bcl-2 family members is essential for the maintenance of mitochondrial integrity, which determines cell survival (23). Within the Bcl-2 family, BH3-only proteins, including Bcl-2-like 11, Bcl-2 binding component 3 or $\mathrm{BH} 3$ interacting domain death agonist (also termed Bim, Puma and Bid, respectively), neutralize antiapoptotic Bcl-2 proteins and directly activate rate-limiting cell death effectors Bax and Bcl-2 antagonist/killer 1 (also termed Bak). Upon activation, these cell death effectors form homodimers and assemble into higher order oligomers that allow the activation of caspase proteases lead to cell death (24). The present study demonstrated that DHM attenuated LPS-induced cardiomyocyte apoptosis by downregulating the expression of Bax, while upregulating Bcl-2 expression, in LPS-stimulated H9c2 cells. These results indicate a potential therapeutic role for DHM in heart disease.

TLR4 has critical roles in mediating inflammatory responses associated with heart diseases (7). TLR4 acts as a pattern recognition receptor, which are receptors that recognize molecular patterns associated with pathogens and damage (25). Once activated, TLR4 triggers an intracellular signaling response and causes the activation and translocation of $N F-\kappa B$ to the nucleus, which leads to an inflammatory response and cell apoptosis. The present study demonstrated that DHM treatment inhibited TLR4 expression and blocked the phosphorylation and nuclear translocation of NF- $\kappa \mathrm{B}$ p65 in response to LPS. This indicates that the alleviating effect of DHM on LPS-induced inflammatory responses and apoptosis in cardiomyocytes may be mediated by inhibition of the TLR4/NF- $\mathrm{B}$ pathway. In conclusion, the present study, to the best of our knowledge, is the first to demonstrate a protective effect of DHM on LPS-induced cardiomyocyte injury via inhibition of the TLR4/NF- $\kappa$ B signaling pathway. These results may be important for the development of strategies for the treatment of heart failure in septic shock. However, further studies are required before DHM may be considered for clinical usage in inflammatory disease.

\section{References}

1. Ramachandran G: Gram-positive and gram-negative bacterial toxins in sepsis: A brief review. Virulence 5: 213-218, 2014.

2. Balija TM and Lowry SF: Lipopolysaccharide and sepsis-associated myocardial dysfunction. Curr Opin Infect Dis 24: 248-253, 2011.

3. McDonald TE, Grinman MN, Carthy CM and Walley KR: Endotoxin infusion in rats induces apoptotic and survival pathways in hearts. Am J Physiol Heart Circ Physiol 279: H2053-H2061, 2000.

4. Ward PA: The sepsis seesaw: Seeking a heart salve. Nat Med 15: 497-498, 2009

5. Zhang Y, Xu X, Ceylan-Isik AF, Dong M, Pei Z, Li Y and Ren J: Ablation of Akt2 protects against lipopolysaccharide-induced cardiac dysfunction: Role of Akt ubiquitination E3 ligase TRAF6. J Mol Cell Cardiol 74: 76-87, 2014.

6. Liaunardy-Jopeace A and Gay NJ: Molecular and cellular regulation of toll-like receptor- 4 activity induced by lipopolysaccharide ligands. Front Immunol 6: 473, 2014. 
7. Liu L, Wang Y, Cao ZY, Wang MM, Liu XM, Gao T, Hu QK, Yuan WJ and Lin L: Up-regulated TLR4 in cardiomyocytes exacerbates heart failure after long-term myocardial infarction. J Cell Mol Med 19: 2728-2740, 2015.

8. Xie J, Liu J, Chen TM, Lan Q,Zhang QY, Liu B, Dai D, Zhang WD, Hu LP and Zhu RZ: Dihydromyricetin alleviates carbon tetrachloride-induced acute liver injury via JNK-dependent mechanism in mice. World J Gastroenterol 21: 5473-5481, 2015.

9. Xia J, Guo S, Fang T, Feng D, Zhang X, Zhang Q, Liu J, Liu B, Li M and Zhu R: Dihydromyricetin induces autophagy in HepG2 cells involved in inhibition of mTOR and regulating its upstream pathways. Food Chem Toxicol 66: 7-13, 2014.

10. Wu S, Liu B, Zhang Q, Liu J, Zhou W, Wang C, Li M, Bao S and Zhu R: Dihydromyricetin reduced Bcl-2 expression via p53 in human hepatoma HepG2 cells. PLoS One 8: e76886, 2013.

11. Shi L, Zhang T, Liang X, Hu Q, Huang J, Zhou Y, Chen M, Zhang Q, Zhu J and Mi M: Dihydromyricetin improves skeletal muscle insulin resistance by inducing autophagy via the AMPK signaling pathway. Mol Cell Endocrinol 409: 92-102, 2015

12. Jiang L, Zhang Q, Ren H, Ma S, Lu C, Liu B, Liu J, Liang J, Li M and Zhu R: Dihydromyricetin enhances the chemo-sensitivity of nedaplatin via regulation of the $\mathrm{p} 53 / \mathrm{Bcl}-2$ pathway in hepatocellular carcinoma cells. PLoS One 10: e0124994, 2015.

13. Hou XL, Tong Q, Wang WQ, Shi CY, Xiong W, Chen J, Liu X and Fang JG: Suppression of inflammatory responses by dihydromyricetin, a flavonoid from ampelopsis grossedentata, via inhibiting the activation of NF- $\mathrm{KB}$ and MAPK signaling pathways. J Nat Prod 78: 1689-1696, 2015.

14. Hou X, Tong Q, Wang W, Xiong W, Shi C and Fang J: Dihydromyricetin protects endothelial cells from hydrogen peroxide-induced oxidative stress damage by regulating mitochondrial pathways. Life Sci 130: 38-46, 2015.

15. Meng G, Yang S, Chen Y, Yao W, Zhu H and Zhang W: Attenuating effects of dihydromyricetin on angiotensin II-induced rat cardiomyocyte hypertrophy related to antioxidative activity in a NO-dependent manner. Pharm Biol 53: 904-912, 2015.

16. Zhu H, Luo P, Fu Y, Wang J, Dai J, Shao J, Yang X, Chang L, Weng Q, Yang B and He Q: Dihydromyricetin prevents cardiotoxicity and enhances anticancer activity induced by adriamycin. Oncotarget 6: 3254-3267, 2015.
17. Livak KJ and Schmittgen TD: Analysis of relative gene expression data using real-time quantitative PCR and the 2(-Delta Delta C(T)) method. Methods 25: 402-408, 2001.

18. Liaudet L: Cardiovascular dysfunction in sepsis: From basic mechanisms to clinical management. Curr Vasc Pharmacol 11: 121-122, 2013.

19. Yu X, Jia B, Wang F, Lv X, Peng X, Wang Y, Li H, Wang Y, $\mathrm{Lu} \mathrm{D}$ and Wang $\mathrm{H}: \alpha_{1}$ adrenoceptor activation by norepinephrine inhibits LPS-induced cardiomyocyte TNF- $\alpha$ production via modulating ERK1/2 and NF- $\kappa$ B pathway. J Cell Mol Med 18: 263-273, 2014

20. Yang P, Han Y, Gui L, Sun J, Chen YL, Song R, Guo JZ, Xie YN, $\mathrm{Lu} \mathrm{D}$ and Sun L: Gastrodin attenuation of the inflammatory response in $\mathrm{H} 9 \mathrm{c} 2$ cardiomyocytes involves inhibition of $\mathrm{NF}-\kappa \mathrm{B}$ and MAPKs activation via the phosphatidylinositol 3-kinase signaling. Biochem Pharmacol 85: 1124-1133, 2013.

21. Zhang H, Wang HY, Bassel-Duby R, Maass DL, Johnston WE, Horton JW and Tao W: Role of interleukin-6 in cardiac inflammation and dysfunction after burn complicated by sepsis. Am J Physiol Heart Circ Physiol 292: H2408-2416, 2007.

22. Yang Z, Liu Y, Deng W, Dai J, Li F, Yuan Y, Wu Q, Zhou H, Bian Z and Tang Q: Hesperetin attenuates mitochondria-dependent apoptosis in lipopolysaccharide-induced H9C2 cardiomyocytes. Mol Med Rep 9: 1941-1946, 2014.

23. Sochalska M, Tuzlak S, Egle A and Villunger A: Lessons from gain- and loss-of-function models of pro-survival Bcl2 family proteins: Implications for targeted therapy. FEBS J 282: 834-849, 2015.

24. Czabotar PE, Lessene G, Strasser A and Adams JM: Control of apoptosis by the BCL-2 protein family: Implications for physiology and therapy. Nat Rev Mol Cell Biol 15: 49-63, 2014.

25. Heiserman JP, Chen L, Kim BS, Kim SC, Tran AL, Siebenborn N and Knowlton AA: TLR4 mutation and HSP60-induced cell death in adult mouse cardiac myocytes. Cell Stress Chaperones 20: $527-535,2015$. 